\title{
SOME PROBLEMS WITH PRESTRESSED CONCRETE SLEEPERS
} DURABILITY

\author{
J. Pawluk ${ }^{1}$, A. Cholewa ${ }^{2}$, W. Kurdowski ${ }^{3}$, W. Derkowski ${ }^{4}$ \\ ${ }^{I}$ TrackTec, Warsaw, Poland \\ ${ }^{2}$ TrackTec, Warsaw, Poland \\ ${ }^{3}$ The Glass and Building Materials Division of the Institute of Ceramics and Building Materials, Cracow, Poland \\ ${ }^{4}$ Cracow University of Technology, Faculty of Civil Engineering, Cracow, Poland
}

\begin{abstract}
In the paper, the authors presented the hazards of concrete sleepers linked with delayed ettringite formation (DEF) as well as the need to maintained of low alkalis content in cement. The authors also discussed the advantages of mechanical anchorage in sleepers, applied in the BBRV technology. This method is based on the system of smooth bars anchorage, on the ends of the strings with higher dimensions and is realized with the anchorage plates. It prevents of microcracks formation after tension release.
\end{abstract}

Keywords: ASR reaction, DEF reaction, reinforcement rebars anchorage $* * *$

\section{INTRODUCTION}

From the eightieth the problems with concrete sleepers deterioration have arose, which was caused by the change of cement technology, from wet to dry method. Numerous research [1-6] have shown that in the majority of cases the main reason of this deterioration was the delayed ettringite formation (DEF). It was also establish in these studies what are the causes of delayed ettringite formation [3, 6, 7]. It seems then that it should end the story of the troubles with concrete sleepers, but it does not the matter. In 2007 in Germany, in the railway line from Berlin to Munich and Hannover million sleepers must be changed, to replace the damaged ones [8]. These sever events, principally from the safety point of view, if the economic problems are even not taken into account, deserve to remind of the rules which assure the durability of concrete sleepers.

\section{THE RULES ASSURING THE CONCRETE}

\section{SLEEPERS DURABILITY}

\subsection{External Destruction Mechanisms}

The causes of external concrete sleepers destruction are rather limited, because the sleepers in the railway lines are positioned on subgrade composed of aggregate ballast. In this conditions the aggressive solutions attack is rather excluded and can take place very seldom. Thus the external attacks are in the majority of cases limited to the frost action. However, this action can be enhanced by the microcracks formed in concrete, which can be caused either by DEF, or by some errors of reinforcing steel bars release in the case of prestressed concrete, which are the sleepers, or by the lack of these reinforced bars anchorage. This problem will be discussed in point 3 .
The sleepers are produced from HPC of the strength in the range from 80 to $90 \mathrm{MPa}$, and the content of high strength cement CEM I 52,5 in concrete is high, as a rule over 300 $\mathrm{kg} / \mathrm{m}^{3}$. There are the reasons that neither frost attack [9] nor carbonation [10] should not represent the serious causes of concrete sleepers destruction.

\subsection{Internal Destruction Mechanisms}

The studies of Heinz and Ludwig [1] have shown that the sleepers destruction was caused by DEF, however, the causes of the instability of ettringite during heat treatment of concrete were establish by Wieker et al. [3]. Wieker [3] found that when the pore solution contains $400 \mathrm{mmol} / \mathrm{l}$ the ettringite is unstable at $75^{\circ} \mathrm{C}$ and is replaced mainly by $\mathrm{C}_{4} \mathrm{AH}_{13}$ [Table 1]. Thus the sulphate ions remain in solution [Fig. 1] and can react with aluminate ions during concrete curing, after different period even two years, that gives expansion.

Table 1: Sulphate phases in equilibrium with $\mathrm{NaOH}$ solution as a function of its concentration and at different temperature [3]

\begin{tabular}{|c|c|c|c|}
\hline \multirow{2}{*}{$\begin{array}{l}\mathrm{NaOH} \\
\text { concentria } \\
- \\
\text { tion } \\
\text { mmoles/l }\end{array}$} & \multicolumn{3}{|c|}{ Detected phases } \\
\hline & $25^{\circ} \mathrm{C}$ & $75^{\circ} \mathrm{C}$ & $100^{\circ} \mathrm{C}$ \\
\hline $\begin{array}{l}0 \\
400 \\
700 \\
1000\end{array}$ & $\begin{array}{l}\text { ett.* } \\
\text { ett. } \\
\text { ett. } \\
\text { ett. }\end{array}$ & $\begin{array}{l}\text { ettringite } \\
\mathrm{Ca}(\mathrm{OH})_{2}, \\
\mathrm{C}_{4} \mathrm{AH}_{13} \\
\mathrm{Ca}(\mathrm{OH})_{2}, \\
\mathrm{C}_{4} \mathrm{AH}_{13} \\
\mathrm{Ca}(\mathrm{OH})_{2}, \\
\text { amorph. phases }\end{array}$ & $\begin{array}{l}\text { ettringite } \\
\mathrm{AFm}, \quad \mathrm{CaSO}_{4}, \\
\mathrm{Ca}(\mathrm{OH})_{2} \\
\mathrm{Ca}(\mathrm{OH})_{2}, \mathrm{CaSO}_{4} \\
\mathrm{C}_{3} \mathrm{AH}_{6}, \quad \mathrm{Ca}(\mathrm{OH})_{2}, \\
\mathrm{CaSO}_{4}\end{array}$ \\
\hline
\end{tabular}

* ett. - ettringit 


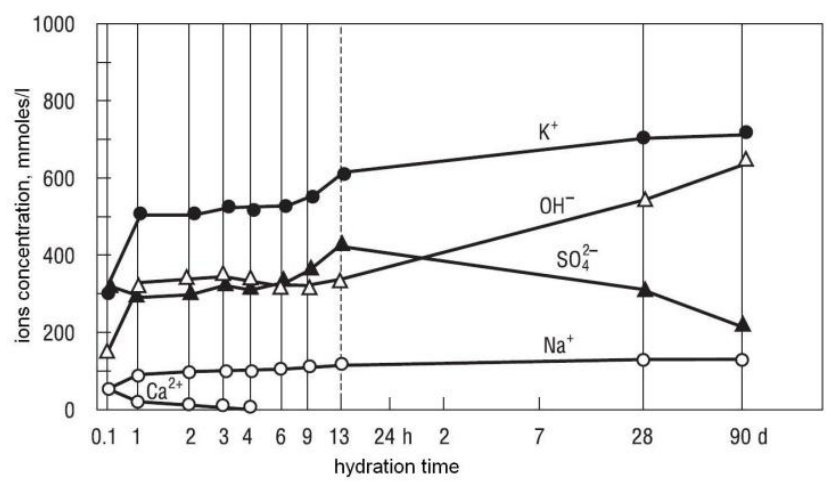

Fig. 1: Composition of the liquid phase in Portland cement paste subjected to thermal treatment at $90^{\circ} \mathrm{C}$ and then cured in water at $20^{\circ} \mathrm{C}$, plotted as a function of time [3]

The time and the intensity of this expansion occurring is depending on the heat treatment temperature [Fig. 2] [3]. The higher the temperature the higher the expansion and shorter the time of its appearing. The expansion is enhanced in the case of the high strength and rapid hardening cements application. Unfortunately in the case of prestressed concrete these type of cements are used.

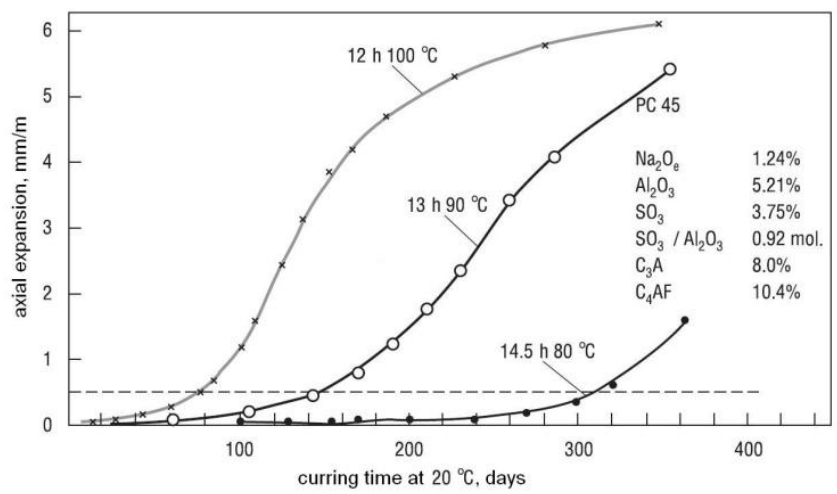

Fig. 2: Expansion of mortars from Portland cement with $\mathrm{Na}_{2} \mathrm{O}_{\mathrm{e}}=1.24$, heat treated at different temperatures (time of curing given on the plots), and subsequently matured at humid atmosphere at temperature of $20^{\circ} \mathrm{C}$ [3].

According to the studies of Wieker [3] and Glasser and Damidot [11] the stability of ettringite during heat treatment depends on the temperature and $\mathrm{SO}_{3}$ content in cement. At the temperature of $70^{\circ} \mathrm{C}$ and the concrete composition, assumed in this paper, Pawluk [12] reported the stability of ettringite at $500 \mathrm{mmol}$ of $\mathrm{NaOH}$ in one litter of solution.

In further consideration we will assume that the concrete composition was as follows: cement $-320 \mathrm{~kg} / \mathrm{m}^{3}, \mathrm{SO}_{3}$ in cement $3 \%$, w/c ratio 0.4 , coarse aggregate $-1600 \mathrm{~kg} / \mathrm{m}^{3}$ and sand $600 \mathrm{~kg} / \mathrm{m}^{3}$. According to these assumptions the theoretical $\mathrm{SO}_{3}$ content in concrete will be about $0.4 \%$. The $\mathrm{SO}_{3}$ content in concrete can always be one of the method for cement content verification.

The analyses of main type of aggregate used in sleepers concrete, i.e. granite and basalt, have shown that the content of soluble, thus reactive alkalis during heat treatment, is as a rule very low, about $0.02 \%$ of $\mathrm{Na}_{2} \mathrm{O}_{\mathrm{e}}$. Thus it will give the
$\mathrm{Na}_{2} \mathrm{O}_{\mathrm{e}}$ mass content in concrete of about $0.32 \mathrm{~kg} / \mathrm{m}^{3}$. In ordinary cement, produced by dry method, the content of total alkalis is about $1.0 \%$ of $\mathrm{K}_{2} \mathrm{O}$ and $0.25 \%$ of $\mathrm{Na}_{2} \mathrm{O}$, and it corresponds to about $0.91 \%$ of total $\mathrm{Na}_{2} \mathrm{O}_{\mathrm{e}}$ and to about $0.8 \%$ of soluble $\mathrm{Na}_{2} \mathrm{O}_{\mathrm{e}}$. In concrete it will give $2.56 \mathrm{~kg} / \mathrm{m}^{3}$. Taking into account the soluble $\mathrm{Na}_{2} \mathrm{O}_{\mathrm{e}}$ in aggregate equal $0.02 \%$, their income to concrete can be calculated as $1600 \mathrm{x}$ $0.0002=0.32 \mathrm{~kg} / \mathrm{m}^{3}$. The total content of soluble $\mathrm{Na}_{2} \mathrm{O}$ in concrete will be $2.98+0.32=3.30 \mathrm{~kg} / \mathrm{m}^{3} .3 .30 \mathrm{~kg}$ is equal to $2448.4 \mathrm{~g}$ of $\mathrm{Na}$, which can form $4258 \mathrm{~g}$ of $\mathrm{NaOH}$ in concrete. It will correspond to $33.27 \mathrm{~g}$ of $\mathrm{NaOH} / 1$ of solution, thus $0.832 \mathrm{mmol} / \mathrm{l}$ of solution. It is much higher than the permissible content establish as $500 \mathrm{mmol} / \mathrm{l}$ [12]. For the heat treated concrete as in the sleepers production it was necessary to apply low alkali cement and in Poland the content of total $\mathrm{Na}_{2} \mathrm{O}_{\mathrm{e}}$ in this cement is lower than $0.6 \%$ and lower than $0,5 \%$ of soluble $\mathrm{Na}_{2} \mathrm{O}_{\mathrm{e}}$. The soluble alkalis content in concrete will be: 0.005 × $320=1.60 \mathrm{~kg} / \mathrm{m}^{3}+0.32$ of $\mathrm{Na}_{2} \mathrm{O}$ from aggregate which gives the total content of $1.92 \mathrm{~kg} / \mathrm{m}^{3}$. It means $1.92 \times 0.742\left[\mathrm{Na} / \mathrm{Na}_{2} \mathrm{O}\right]=1.425 \mathrm{~kg}$ of $\mathrm{Na}$. It corresponds to $2.48 \mathrm{~kg}$ of $\mathrm{NaOH}$ and $19.38 \mathrm{~g} / \mathrm{l}$ of solution and $485 \mathrm{mmol} / \mathrm{l}$. It is lower then found by Pawluk [12] threshold value. If we take, as a limit for total alkali content in cement $0.8 \%$ [soluble $0,7 \%$ ], calculation shows that it will correspond to $2.24 \mathrm{~kg}$ of $\mathrm{Na}_{2} \mathrm{O} \mathrm{kg} / \mathrm{m}^{3}$ and +0.32 $\mathrm{Na}_{2} \mathrm{O}$ from aggregate $=2.56 \mathrm{~kg} / \mathrm{m}^{3}$. It gives $1.90 \mathrm{~kg}$ of $\mathrm{Na}$ which corresponds to $3.3 \mathrm{~kg}$ of $\mathrm{NaOH}$ and $25.8 \mathrm{~g} / \mathrm{l}$ of solution and $645 \mathrm{mmol} / \mathrm{l}$, which is much higher than the threshold value [12]. It was the cause that in concrete with cement containing $0.78 \%$ of soluble alkalis ettringite was not stable at heat treatment at $70^{\circ} \mathrm{C}$.

It should be also underlined that the low alkalis content in cement is also an efficient method for hindering of the alkali silica reaction in the case of reactive aggregate usage in concrete production [13].

\section{PROBLEM OF SLEEPERS}

\section{REINFORCEMENT}

In typical prestressed concrete elements the tensioning force is transmitted on concrete through the adhesion of the strings and cover of hardened concrete. The constrains of adhesion are usually defined as the tangential stress, uniformly distributed on the string surface. At this surface the mechanism of adhesion are the following: chemical adhesion, friction on the contact of steel bar with concrete and mechanical meshing. The chemical adhesion is causing the compressive strength on the bond of steel bar with concrete, however, it can be broken, even at very low slip of the string in concrete cover. In Fig. 3 the adhesion stress in non-cracked concrete is presented in the initial section of the diagram, ranging to point A [14].

The chemical adhesion can be also broken by the microcracks formation in concrete, in the neighbourhood of string. It is assumed that the tensioning force of steel bars in concrete is in the range from 0.5 to $1.0 \mathrm{MPa}$. 
The friction of steel bar with concrete is very important in transmitting forces between this bar and concrete and depends in high degree of the string shape. It even can represent of $35 \%$ of final tensioning strength of concrete.

The mechanical meshing, formed on the bars surface roughness, has a decisive influence on concrete tensioning to the reinforcement. It depend significantly on the string surface and nowadays the bars with deformed surface, or multi-weaves wires, are commonly used in prestressed elements. When the maximum bond strength is reaching the microcracks in concrete wedge are beginning to form, in the strings pockets and the slip is appearing. It can be caused also, in minor degree, by shrinkage or other concrete volume changes.

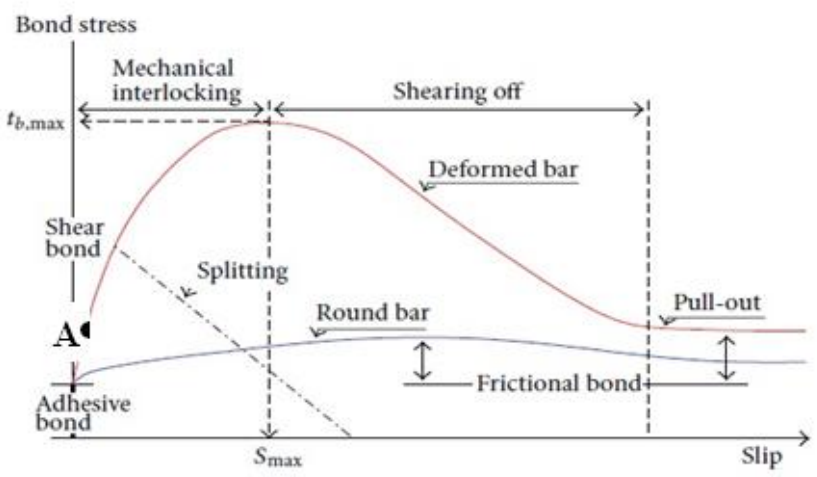

Fig. 3: Typical relations of tensioning stress from slip [15].

In classic prestressed concrete elements the total tensioning force on concrete is transmitted in section of length $l_{p t}$, called the transmission length. Out of this section the compressive stresses of tensioning are successively propagating on whole element intersection. The linear distribution of this stresses propagation appear only in the intersection at the distance from the element front equal $l_{\text {disp }}$. These both section are shown on Fig. 4.
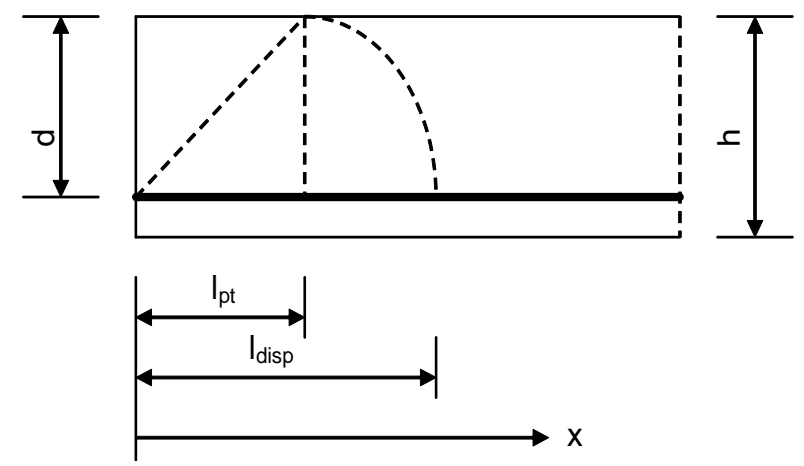

Fig. 4: The transmission and propagation sections length in prestressed concrete element

The length of these sections depend significantly on concrete mechanical properties, chiefly of the tension strength, but also on hardness, and on tensioning force and string diameter.
In the case of such specific construction as prestressed concrete mono-block sleepers the transmission length is a main designing parameter, because the very high effort of the under-rail zone, is relatively close located to the sleeper front.

The transmission of tensioning force to the sleeper front zone, in which the strings are anchored by tensioning only, causes the composed, spacial stresses state, composed of the longitudinal stress streams, compressing concrete (parallel to the sleeper axis) and the lateral tensile stresses. The recently published Model Code 2010 [16] is defining three types of cracks formation in the sleeper front of prestressed concrete, which can have basic effect on correct strings anchorage in concrete:

- bursting effect - designed as ,1” in Fig. 5, caused by lateral tensile stresses in concrete,

- $\quad$ spalling effect - designed as „2” on Fig. 5, in the end zones of concrete elements, particularly with thin-walls ones,

- $\quad$ splitting effect - designed as , 3 ", near the contact surface with the string, caused mostly by to close placed the neighboring strings.

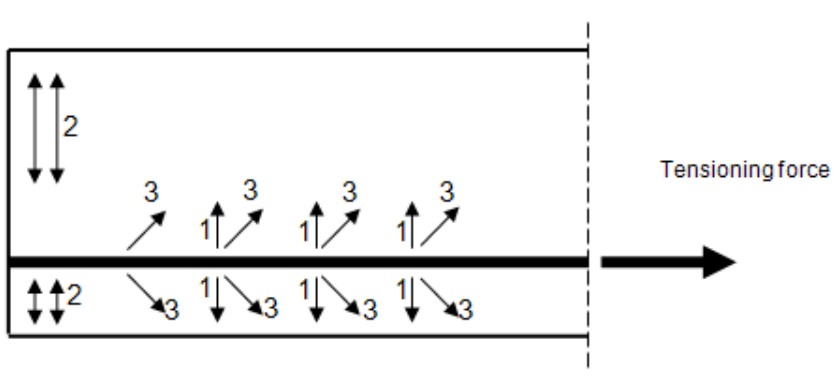

Fig. 5: The stress streams directions and possible damage of near-front zone of prestressed concrete element [16].

Splitting phenomenon can be easily prevented by confined concrete with suitably shaped bars, for example in the form of stirrup. According to the MC [16] recommendations to prevent the cracks formation in the contact zone with the string the minimum spacing between strings assuring, not lower than $(2 \div 3) \emptyset_{s}$ (where $\varnothing_{s}$ is the nominal string diameter) and minimum string cover, not lower than $(2,5 \div 4)$ $\emptyset \mathrm{s.}$

Frequently the aforementioned phenomena are superimposing and their total effect can lead to the total loss of load capacity, of whole element.

It will be interesting to describe the prestressed concrete sleepers with strings in the form of weaves, composed of three smooth wires with the diameter of three $\mathrm{mm}$ (weave $\left.\varnothing_{\mathrm{s}} \approx 6,5 \mathrm{~mm}\right)$. The weaves were situated in two groups placed vertically, one above the second. These sleepers were frequently damaged.

The front of this sleeper is such configurated, that the ends of particular tensioning string groups were placed in the concrete tongue, of relatively low width. In the near-front zones the concrete confining was not applied. 


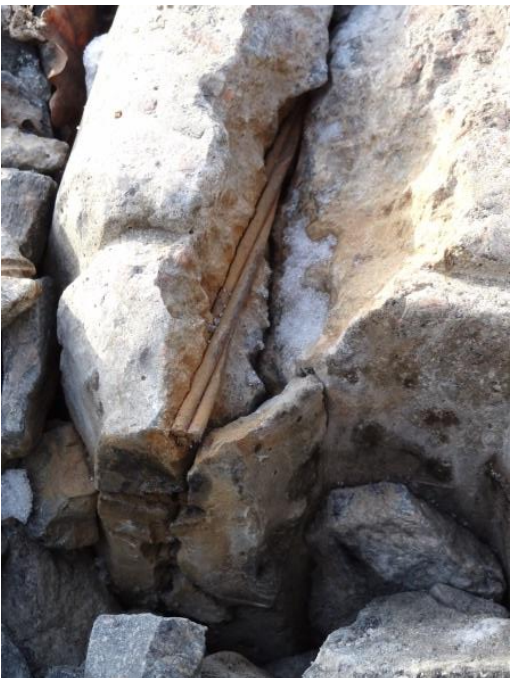

Fig. 6: The damaged sleeper front; [source the authors archive].

The defects, in the form of concrete cracking and significant spalling, are caused by incorrect designing of the sleepers near-front zone. In these damage probably all the defects defined in the MC [16] instruction take place. The cumulating of the relatively high tensioning force, due to several weaves placed at low distance, caused the microcracks due to the significant transverse deformation of highly compressed concrete i.e. spalling effect and bursting effect. This effect should occurs in the place in which several strings were placed, with low spacing. Applying in the sleepers ends the tongues with low transverse intersection of concrete without circumferential reinforcement, caused spalling effect. However, the phenomenon of unsymmetrical damage of sleeper is probably due to the non-uniform tension release, during sleepers production.

The majority of described damage of near-front zone of the sleepers were formed probably at tensioning release of concrete, but their intensity were significantly lower. Only the cyclic, dynamic loading caused by railway exploitation and frost action, caused the significant development of these damage.

The attention should be also paid to the lack of corrosion protection of tensioning weaves ends in the case of reinforcing strings anchorage only through adhesion.

The alternative solution to the aforementioned anchorage of tensioning strings in sleepers is the method with mechanical anchorage, applied in the BBRV technology, which is used in several European countries, also in Poland. The system of smooth bars (diameter of 7 to $8 \mathrm{~mm}$ ) anchorage, on the ends of the strings with higher dimensions, is realized with the anchorage plates. Tensioning is solved through the tensioning screws in the anchor aging plates, placed at some distance from the element front. This solution is shown in the Fig. 7 and its position in the mould, before concrete placing, in Fig. 8.

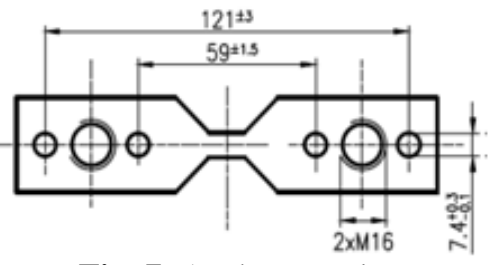

Fig. 7: Anchorage plate

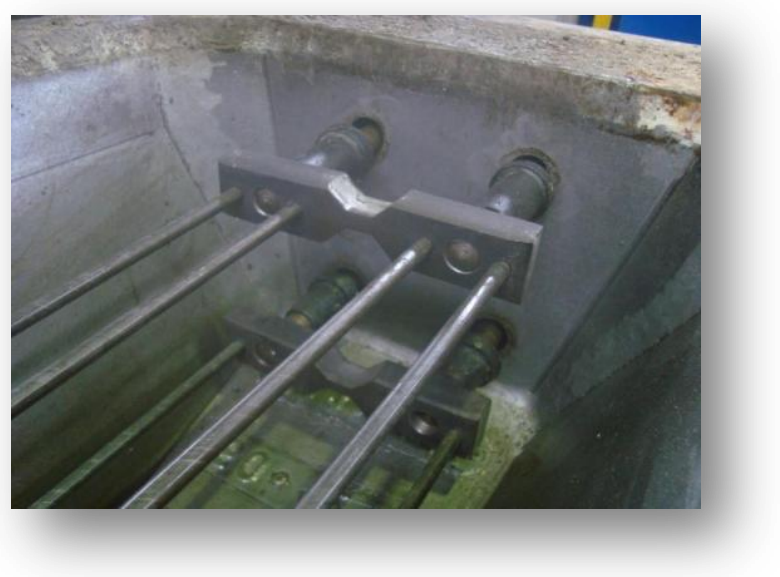

Fig. 8: The damaged sleeper front. Source the authors archive.

\section{FINAL REMARKS}

In to prevent the prestressed concrete sleepers from damage and assure their durability some fundamental rules must be observed. There are the following:

- $\quad$ assure the usage of low alkali cement,

- the temperature of heat treatment must not exceeds $70^{\circ} \mathrm{C}$, inside the concrete elements,

- the application of BBRV technology should be seriously taken into account.

The studies of four different systems of strings anchorage, carried out in 2013 in Technical University in Kraków, have shown that the BBRV technology is assuring the highest load ability of sleepers by 23 to $36 \%$.

\section{REFERENCES}

[1]. Heinz D., Ludwig U., 8th ICCC Rio de Janeiro, vol. V, p. 189, Rio de Janeiro 1986.

[2]. Heinz D., Ludwig U., Rudger L., Concrete Pecasting Plant and Technology, 11, 56 (1989).

[3]. Wieker W., Herr R., Schubert H., Proc. Int. Coll. Corrosion of Cement Paste, Mogilany 16-17 November (ed. W. Kurdowski), p. 3, Kraków 1994.

[4]. Kelham S., Cem. Contr. Composites, 18, 171 (1996).

[5]. Kelham S. 10th ICCC Göteborg, vol. IV, paper 4IV059, Göteborg 1997.

[6]. Wieker W., Scrivener K. L., 9th ICCC New Delhi, vol. I, p. 449, New Delhi 1992.

[7]. Glasser F. P., Damidot D., Atkins M., Adv. Cem. Res., 26, 57 (1995).

[8]. Schmitt J., Pfusch am Gleis, Der Spiegel 10/2008. 
[9]. Pigeon M. and Pleau R., Durability of concrete in cold climates, Taylor \& Francis, London 1995.

[10]. Nagataki S., Ohga H., Kyum Kim E., Proc. 2nd Int. Conf. on Fly Ash, Silica Fume, Slag and Natural Pozzolanas in Concrete (ed. V. M. Malhotra), ACI SP-91, p. 521, Madrid 1986.

[11]. Glasser F. P., Damidot D., Atkins M., Adv. Cem. Res., 26, 57 (1995).

[12]. Pawluk, submitted for publication in Cement Wapno Beton.

[13]. Oberholster R. E., Wan Aardt J. H. P., Brandt M. P., w „Structure and Performance of Cements” (ed. P. Barnes), p. 365, Appl. Science Publ., London 1983.

[14]. Hosseini, S. J. A.; Koushfar, K; Rahman, A.B; Razavi, M., "The bond behaviour in reinforced concrete, state of the art", Cement, Wapno, Beton, 2, 2014.

[15]. Sungnam Hong Sun-Kyu Park, Uniaxial Bond StressSlip Relationship, Advances in Materials Science and Engineering, Aericle ID 328570, 12 pages [2012].

[16]. „Model Code 2010 - Final draft”, fib Bulletin 65 and 66, Swiss Federal Institute of Technology Lausanne, Switzerland, 2012.

\section{BIOGRAPHIES}

J. Pawluk - the graduate of Fachhochschule Niederrhein, Germany, Faculty of Chemistry, Chemical Technology, President and Chief Executive Officer, Track Tec S.A.

A. Cholewa - the graduate of Silesian University of Technology, Faculty of Automatic Control, Electronics and Computer Science, Ph. D. - Warsaw School of Economics, Member of the Board, Chief Technical Officer, Track Tec. S.A.

W. Kurdowski - professor at The Glass and Building Materials Division of the Institute of Ceramics and Building Materials in Cracow. Expert in cement chemistry.

W. Derkowski - Ph. D., lecturer in Building engineering branch, Faculty of Civil Engineering, Cracow University of Technology. 